\title{
Is it Worth the Effort? Novel Insights into Obesity-Associated Alterations in Cost-Benefit Decision-Making
}

\author{
David Mathar ${ }^{1,2 *}$, Annette Horstmann ${ }^{1,2}$, Burkhard Pleger ${ }^{1,2,3}$, Arno Villringer $^{1,2,3,4}$ and \\ Jane Neumann ${ }^{1,2}$ \\ ${ }^{1}$ Department of Neurology, Max Planck Institute for Human Cognitive and Brain Sciences, Leipzig, Germany, ${ }^{2}$ IFB Adiposity \\ Diseases, Leipzig University Medical Center, Leipzig, Germany, ${ }^{3}$ Clinic of Cognitive Neurology, University Hospital Leipzig, \\ Leipzig, Germany, ${ }^{4}$ Berlin School of Mind and Brain, Mind and Brain Institute, Humboldt-University, Berlin, Germany
}

OPEN ACCESS

Edited by: Carmen Sandi,

École Polytechnique Fédérale de Lausanne, Switzerland

Reviewed by:

Roee Admon,

McLean Hospital, Harvard Medical School, USA Michael Arthur Van Der Kooij, Johannes Gutenberg University Mainz, Germany

*Correspondence: David Mathar mathar@cbs.mpg.de

Received: 01 October 2015 Accepted: 14 December 2015 Published: 12 January 2016

Citation:

Mathar D, Horstmann A, Pleger B Villringer $A$ and Neumann $J$ (2016) Is it Worth the Effort? Novel Insights into

Obesity-Associated Alterations in Cost-Benefit Decision-Making.

Front. Behav. Neurosci. 9:360.

doi: 10.3389/fnbeh.2015.00360
Cost-benefit decision-making entails the process of evaluating potential actions according to the trade-off between the expected reward (benefit) and the anticipated effort (costs). Recent research revealed that dopaminergic transmission within the fronto-striatal circuitry strongly modulates cost-benefit decision-making. Alterations within the dopaminergic fronto-striatal system have been associated with obesity, but little is known about cost-benefit decision-making differences in obese compared with lean individuals. With a newly developed experimental task we investigate obesity-associated alterations in cost-benefit decision-making, utilizing physical effort by handgrip-force exertion and both food and non-food rewards. We relate our behavioral findings to alterations in local gray matter volume assessed by structural MRI. Obese compared with lean subjects were less willing to engage in physical effort in particular for high-caloric sweet snack food. Further, self-reported body dissatisfaction negatively correlated with the willingness to invest effort for sweet snacks in obese men. On a structural level, obesity was associated with reductions in gray matter volume in bilateral prefrontal cortex. Nucleus accumbens volume positively correlated with task induced implicit food craving. Our results challenge the common notion that obese individuals are willing to work harder to obtain high-caloric food and emphasize the need for further exploration of the underlying neural mechanisms regarding cost-benefit decision-making differences in obesity.

Keywords: obesity, cost-benefit decision-making, physical effort, reward, voxel-based morphometry

\section{INTRODUCTION}

Everyday decisions are guided by cost-benefit analyses. For example, whether or not we choose to walk to the next store to buy chocolate depends not only on how much we like chocolate and on our present state of hunger, but also on our subjective perception of the distance to the next store. Thus, we weigh the expected rewards an action will deliver against the effort for obtaining them to calculate a subjective utility value that guides our decisions.

Several studies have revealed that perceived effort strongly impacts on our decisions and that the fronto-striatal pathway is critical for integrating effort costs to form a decision in both animals and humans (Salamone et al., 1994; Bautista et al., 2001; Walton et al., 2002, 2006; Croxson et al., 2009; Basten et al., 2010). Mesolimbic dopamine was shown to play a key 
role in the motivation to overcome costs in order to receive rewards (Salamone et al., 1994, 2007; Kurniawan et al., 2011; Salamone and Correa, 2012; Treadway et al., 2012). In particular nucleus accumbens (NAcc) dopamine is believed to modulate motivational salience in goal-directed behavior (Salamone and Correa, 2012).

In the case of obesity, identifying possible alterations in cost-benefit decision-making is of particular importance. In our obesogenic environment potent food is always available at minimal costs, and excess weight is associated with a reduced motivation for physical activity (Ness et al., 2007) and a possibly heightened valuation of potent food rewards (e.g., Rothemund et al., 2007).

Obesity has been characterized by a reduced binding potential of striatal dopamine receptors (Wang et al., 2001; de Weijer et al., 2011). This is hypothesized to be associated with a heightened striatal dopaminergic tone (Horstmann et al., 2015b). Further, obese individuals show a heightened neural activation during the anticipation of high-caloric food stimuli in dopaminergic target regions such as NAcc in the context of reward processing (e.g., Stice et al., 2008; Nummenmaa et al., 2012). This foodrelated hyper-responsiveness may point at a context-sensitive dopaminergic reward system, possibly mediated through foodrelated memory input from the ventral subiculum of the hippocampus (Belujon and Grace, 2011).

To date, only few studies have explored obesity-associated alterations in cost-benefit decision-making in humans. Two studies indicate that obese subjects may be willing to invest more effort to obtain high-caloric food than lean individuals (Epstein et al., 2007; Giesen et al., 2010). Both studies used button presses as a measure of physical effort and assessed obesity-associated alterations in cost-benefit decisions solely with respect to food reward. It is thus not clear if the results generalize to other reward categories. Further, findings in rodents related to costbenefit decision-making in obesity are mixed, with some studies showing a heightened willingness to work for food rewards in diet-induced obese animals (e.g., Narayanaswami et al., 2013) and others revealing the opposite (e.g., Harb and Almeida, 2014).

Thus, there is need for a systematic investigation of costbenefit decision-making in obesity that involves properly demanding physical effort measures and food and non-food reward categories.

Importantly, cost-benefit decision-making, with its strong reliance on dopaminergic pathways, may be modulated by a multitude of factors, in addition to obesity. Hence, a thorough investigation of obesity-associated cost-benefit decision making necessitates the inclusion of possible confounding factors. Gender has been revealed to alter dopaminergic neurotransmission, and recently estradiol was shown to modulate dopamine baseline dependent cognitive functioning in humans (Haaxma et al., 2007; Jacobs and D'Esposito, 2011) and cost-benefit decision-making in rodents (Uban et al., 2012). Further, gender has been shown to modulate obesity-related differences in brain structure and related processes of cognitive control (Horstmann et al., 2011). In the context of reinforcement sensitivity theory, reward and punishment sensitivity are both known to rely on dopaminergic activity (Maril et al., 2013; Tomer et al., 2014) and may impact sensitivity to rewards and effort demands in cost-benefit decisions. Further, both are associated with eating behavior (Loxton and Dawe, 2006; Matton et al., 2013; Dietrich et al., 2014). In the case of obesity, additional psychosocial factors, such as concerns about one's own body image, may modulate food-related cost-benefit decisions. Following findings regarding stigmata in obesity (e.g., Forste and Moore, 2012), one would for example expect self-reported body dissatisfaction to decrease motivation to invest effort for high-caloric food specifically in obese women. As a potent environmental factor affecting effort-based decision-making, stress was shown to modulate dopaminergic transmission within the fronto-striatal system (Nagano-Saito et al., 2013; Pruessner et al., 2013) and to reduce intrinsic motivation to invest effort in rodents (Shafiei et al., 2012). Stress has also been linked to eating behavior and body weight (Warne, 2009; Tomiyama et al., 2011).

In this study we investigate obesity-associated alterations in cost-benefit decision-making and in related reaction times regarding physical effort and different kinds of food and nonfood rewards. We designed a novel cost-benefit decision-making paradigm in which subjects can choose to invest physical effort via a digital handgrip device to receive rewards out of three distinct categories: money, fruit and sweet high-caloric snacks. We hypothesize that obese compared with lean subjects show alterations in cost-benefit decision-making particularly in relation to high-caloric sweet snack food. We expect that gender and subjects' self-reported body dissatisfaction strongly modulate willingness to exert effort for sweet snacks in obese participants. Obese participants with high body dissatisfaction may be less driven to invest effort for high-caloric food reward compared with lean subjects. The impact of body dissatisfaction on subjects' cost-benefit decisions may be more prominent in women than in men. Further, we expect that perceived chronic stress level negatively correlates with subjects' motivation to invest effort. As physical effort may be experienced as a sort of punishment, high punishment sensitivity may reduce willingness to exert effort, whereas heightened reward sensitivity may enhance willingness to invest effort to receive rewards.

Beyond behavioral assessment, we apply voxel-based morphometry (VBM) in a subsample of our subjects. Based on recent findings (Schäfer et al., 2010; Horstmann et al., 2011), we hypothesize that obese compared with lean subjects show lower gray matter volume in cognitive-control related lateral prefrontal cortices (lPFC) and possibly higher gray matter volume in areas implicated in reward processing such as orbitofrontal cortex (OFC) and NAcc. We expect that volume of NAcc, as the dopaminergic core brain structure involved in the motivation to overcome costs to obtain rewards, positively correlates with subjects' willingness to exert effort. In addition, as NAcc activation has been related to craving severity (Kober et al., 2010) and its gray matter volume to eating behavior pathology and addiction-like behavior (Schäfer et al., 2010; Howell et al., 2013), we predict that NAcc gray matter volume positively correlates with task induced craving for high-caloric food. 


\section{MATERIALS AND METHODS}

\section{Subjects}

The study was carried out in compliance with the Declaration of Helsinki and approved by the local ethics committee of the University of Leipzig. We included 57 healthy Caucasian participants who were separated into four groups according to their BMI and gender: two obese $(\mathrm{BMI} \geq 30$, BMI < 40) groups with 14 female and 15 male participants, and two lean control groups (BMI $\geq 19$, BMI $\leq 25$ ), consisting of 15 female and 13 male subjects. The four groups were closely matched for educational background (i.e., years of scholastic education) and age distribution (Table 1). All participants were right-handed (Edinburgh Handedness Inventory, (Oldfield, 1971)), between 18 and 35 years old and reported to generally like fruits and sweets. Exclusion criteria were hypertension, dyslipidemia, metabolic syndrome, depression [Beck Depressions Inventar (BDI), Hautzinger, 1995 (german version of the Beck Depression Inventory (BDI-II), Beck et al., 1996; cut-off value 18; Table 1], a history of neuropsychiatric diseases, smoking, and diabetes mellitus type I and II. All subjects gave written informed consent before taking part in the study.

\section{Stimuli}

In our experiment, subjects could earn rewards from three distinct categories: money, fruit, and sweet snacks, and in two quantities: one or four pieces. Money was represented by two cent coins. Available fruit items included pieces of apple, banana, kiwi, nectarine, orange, pear, physalis, pineapple, raisins, and strawberries. Sweet snack items consisted of different small chocolate bars from Mars' celebration collection (Bounty, Dove, Dove-Caramel, Mars, Milkyway, Snickers, Teaser, Twix) and four different gummi bear-like snacks (Haribo Goldbären, Haribo Konfekt, Haribo Vampire, and Saure Apfelringe). During the task, reward stimuli were presented as photographs of the respective reward item that showed either one or four pieces, indicating the quantity of the reward item subjects could earn in the respective trial.

To earn the rewards during the task, subjects had to exert handgrip force. Force levels consisted of an easy and a hard category, with force levels drawn from two normal distributions with mean 50 or $67 \%$ and standard deviation $2 \%$ of subjects' individual maximum handgrip forces. A thermometer on the screen indicated the proposed level.

Before being instructed, subjects' maximum handgrip force was assessed with an isometric handgrip device (BIOPAC, TSD121) to individually adjust effort levels in the subsequent task. To familiarize participants with the task, they performed 10 practice trials beforehand. During the task, subjects made their choices with a response pad in their left hand and exerted effort with the isometric handgrip device in their right hand. Subjects' right hand was videotaped to assure that subjects only gripped with their right hand during the task.

\section{Visual Analog Scale (VAS) Rating and Questionnaires}

Subjects were told to refrain from eating $3 \mathrm{~h}$ before the experiment when they were invited. When they entered the lab, subjects completed several questionnaires related to body dissatisfaction (EDI-2, Paul and Thiel, 2005; Table 1), reward and

TABLE 1 | Sample size, distribution of body mass index (BMI), age, years of education, depressive symptoms (BDI), punishment sensitivity (BIS), reward sensitivity (BAS), chronic stress level (TICS), self-reported body dissatisfaction, VAS hunger rating prior to experiment, task-induced implicit food craving, nine-point Likert Scale rating of subjects' wanting and liking of the individual sweet snack and fruit items that entered the task, subjects' maximum hand grip force, average reaction times and fraction of choices to exert effort throughout the task.

\begin{tabular}{|c|c|c|c|c|c|c|}
\hline & Lean women & Obese women & Lean men & Obese men & $F$-/H-values & $p$ \\
\hline Sample size (sample size MRI) & $15(12)$ & $14(8)$ & $13(11)$ & $15(11)$ & - & - \\
\hline BMl & $22.1 \pm 1.3$ & $33.6 \pm 2.0$ & $21.4 \pm 1.3$ & $33.5 \pm 2.6$ & $F_{(3,53)}=182.11$ & $<0.001$ \\
\hline Age & $24.3 \pm 3.0$ & $26.5 \pm 4.5$ & $26.1 \pm 3.0$ & $27.5 \pm 3.6$ & $F_{(3,53)}=2.05$ & 0.12 \\
\hline Years of education & $13(13-13)$ & $13(10-13)$ & $13(13-13)$ & $13(10-13)$ & $H_{(3)}=3.89$ & 0.27 \\
\hline $\mathrm{BDI}$ & $2.7 \pm 2.9$ & $6.1 \pm 5.1$ & $3.5 \pm 4.0$ & $4.5 \pm 4.5$ & $H_{(3)}=3.90$ & 0.27 \\
\hline BIS & $19.2 \pm 2.5$ & $18.8 \pm 2.7$ & $18.4 \pm 3.3$ & $17.7 \pm 3.7$ & $F_{(3,53)}=0.67$ & 0.58 \\
\hline BAS & $38.3 \pm 9.3$ & $37.9 \pm 8.1$ & $41.1 \pm 4.9$ & $37.6 \pm 9.0$ & $F_{(3,53)}=0.48$ & 0.70 \\
\hline TICS & $16.8 \pm 7.5$ & $18.4 \pm 9.2$ & $15.2 \pm 7.1$ & $16.9 \pm 9.7$ & $F_{(3,53)}=0.30$ & 0.82 \\
\hline Body dissatisfaction & $29.8 \pm 10.3$ & $44.1 \pm 8.8$ & $16.0 \pm 5.3$ & $38.5 \pm 10.8$ & $F_{(3,53)}=22.62$ & $<0.001$ \\
\hline Hunger prior to experiment & $59.4 \pm 22.7$ & $56.2 \pm 28.1$ & $53.3 \pm 20.7$ & $58.6 \pm 19.5$ & $F_{(3,53)}=0.02$ & 0.89 \\
\hline Implicit food craving & $22.7 \pm 18.3$ & $32.4 \pm 25.3$ & $21.7 \pm 20.3$ & $17.6 \pm 15.8$ & $F_{(3,53)}=1.43$ & 0.24 \\
\hline Wanting of included sweet items & $7.7 \pm 1.1$ & $7.2 \pm 1.0$ & $7.5 \pm 1.0$ & $6.7 \pm 1.4$ & $H_{(3)}=5.82$ & 0.12 \\
\hline Wanting of included fruit items & $8.1 \pm 0.8$ & $7.6 \pm 1.1$ & $7.9 \pm 1.0$ & $7.8 \pm 0.8$ & $H_{(3)}=2.39$ & 0.50 \\
\hline Liking of included sweet items & $8.1 \pm 0.9$ & $7.3 \pm 0.8$ & $7.5 \pm 0.9$ & $7.1 \pm 0.9$ & $H_{(3)}=8.13$ & $<0.05$ \\
\hline Liking of included fruit items & $8.3 \pm 0.7$ & $7.8 \pm 0.8$ & $8.1 \pm 1.0$ & $8.2 \pm 0.8$ & $H_{(3)}=4.33$ & 0.23 \\
\hline Maximum grip force & $27.1 \pm 5.5$ & $27.1 \pm 5.6$ & $43.1 \pm 6.9$ & $48.1 \pm 9.2$ & $F_{(3,53)}=34.96$ & $<0.001$ \\
\hline Reaction times & $581.9 \pm 74.1$ & $672.3 \pm 106.6$ & $569.1 \pm 62.9$ & $614.2 \pm 105.8$ & $F_{(3,53)}=3.63$ & $<0.05$ \\
\hline$\%$ Choices of effort exertion & $64.4 \pm 15.0$ & $65.4 \pm 18.7$ & $71.4 \pm 17.0$ & $56.6 \pm 11.1$ & $F_{(3,53)}=2.17$ & 0.10 \\
\hline
\end{tabular}

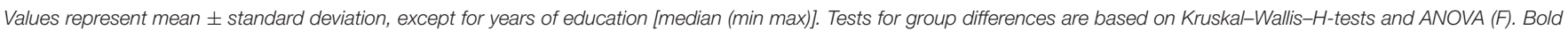
values represent significant group differences. 
punishment sensitivity (German version of BIS/BAS scale, Carver and White, 1994; Strobel et al., 2001; Table 1), and chronic stress levels (TICS, Schulz et al., 2004; Table 1). Prior to performing the task, subjects were asked to rate how hungry they felt on a VAS (range: 0-100; 0, not hungry at all; 100, extremely hungry), to control for differences in hunger. After the task subjects were asked to rate their state of hunger again. We used the hunger difference before and after the task as an implicit measure of task-induced food craving.

\section{Food Item Rating}

To control for individual liking and wanting of the food items that entered the task, we assessed subjects' liking and wanting of the food items. Specifically, subjects were presented pictures of all food items on the computer screen in a randomized order and asked to rate them according to how much they liked the respective food. Subsequently, subjects were asked to rate the food items with respect to how much they wanted to eat the different food items right now. Liking and wanting ratings were obtained utilizing nine-point Likert scales, ranging from "not at all" (1) to "very much" (9). For each subject, the five "most wanted" sweet snacks and fruit items were chosen as stimuli in the subsequent cost-benefit task.

\section{Task}

In each trial of the task (Figure 1A), subjects were shown a picture of the available reward item (one or four pieces of the sweet snack, fruit, or money) and the required effort level they had to invest (high or low, indicated by a thermometer). In half of the trials, the order of reward and effort presentation was reversed. Subsequently, subjects decided whether they wanted to exert the effort level to receive the reward item or not. Subjects were instructed to decide as fast as possible. Reward and effort presentation each lasted for $1500 \mathrm{~ms}$ followed by a $2000 \mathrm{~ms}$ time interval where subjects had to indicate on a two button response pad in their left hand, whether they wanted to exert the respective

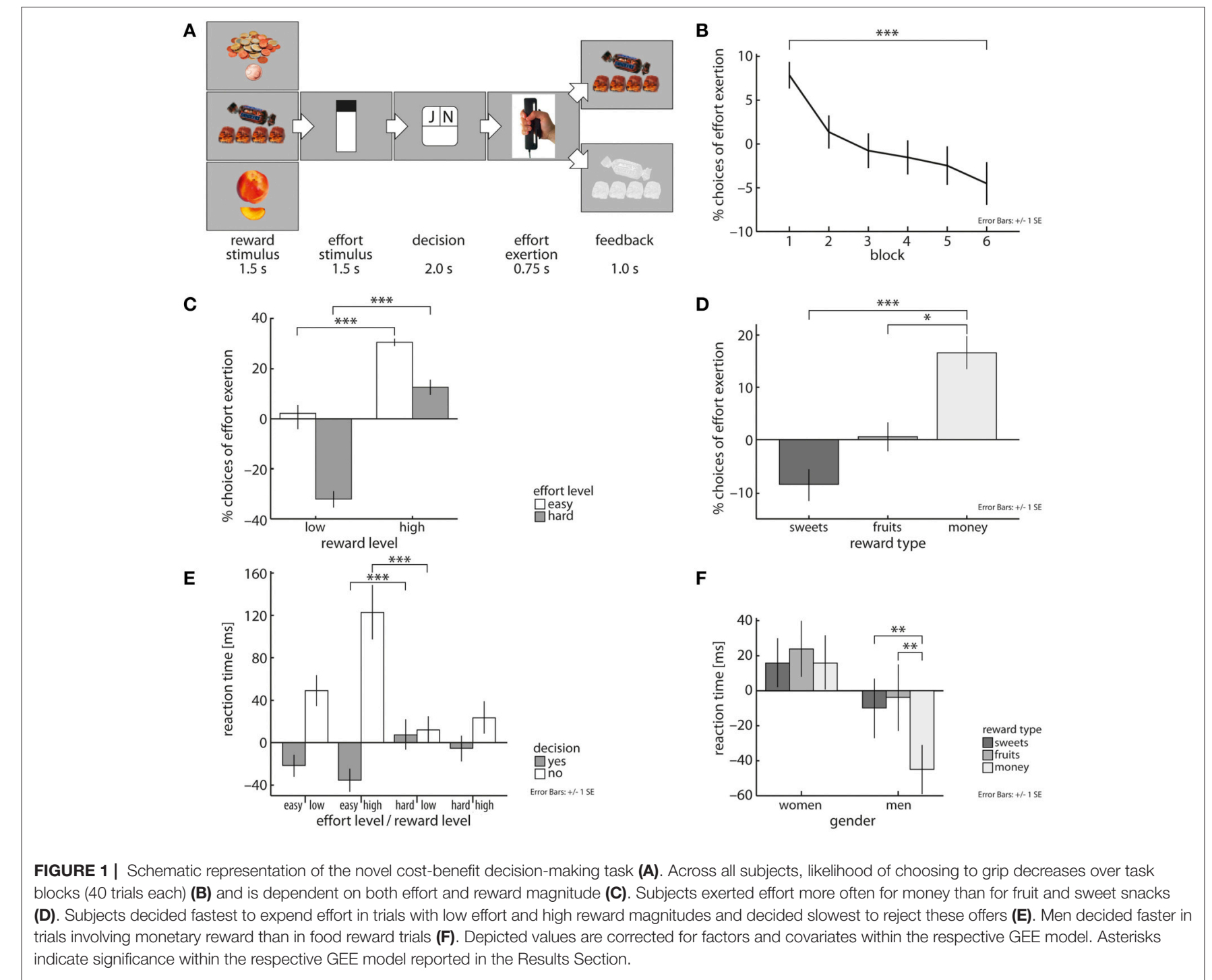


effort level to receive the anticipated reward, or not. If they did not respond in time, a frowney appeared on the screen together with the instruction "too slow." Assignment of "yes" and "no" to the two response buttons was randomized over trials. After the decision, subjects either had to grip the required force level or passively waited for $2000 \mathrm{~ms}$. If they chose to grip, subjects had to squeeze the hand grip device until the indicated level was reached on the thermometer within $2000 \mathrm{~ms}$ and had to maintain this force level for $750 \mathrm{~ms}$. If subjects successfully finished the effort exertion phase, they received a positive feedback that consisted of a smiley and the earned reward displayed for $1000 \mathrm{~ms}$. If they failed to do so or had chosen not to grip, they received negative feedback in the form of a frowney and a masked picture of the reward. The next trial started after an inter-trial-interval of $2000 \mathrm{~ms}$. Reward category, reward and effort level and trial order (reward first/effort first) were randomized over the whole task and each block.

The task consisted of six blocks (lasting $\sim 10 \mathrm{~min}$ ) composed of 40 trials each, leading to a total of 240 trials. Between trial blocks, subjects had 3 min time to relax their right hand from gripping. At the end of the task, subjects' maximum grip force was assessed again, to exclude that cost-benefit decisions were influenced by fatigue. Finally, subjects were paid a compensation of $7 € / \mathrm{h}$ and received their earned sweet snacks, fruit pieces and additional reimbursement of up to $3 €$ according to their gained reward across money trials.

\section{MRI Acquisition}

We acquired T1-weighted images in a subsample of 42 [20 female, 19 (8 female) obese] participants on a whole-body 3T TIM Trio scanner (Siemens, Erlangen, Germany) with a 12-channel head-array coil using a MPRAGE sequence [TI = $650 \mathrm{~ms}$; TR = $1300 \mathrm{~ms}$; snapshot FLASH, TRA = $10 \mathrm{~ms}$; TE = $3.93 \mathrm{~ms} ; \alpha=10^{\circ}$; bandwidth $=130 \mathrm{~Hz} /$ pixel (i.e., $67 \mathrm{kHz}$ total); image matrix $=256 \times 240 ; \mathrm{FOV}=256 \times 240 \mathrm{~mm}$; slab thickness $=192 \mathrm{~mm}$; 128 partitions; $95 \%$ slice resolution; sagittal orientation; spatial resolution $=1 \times 1 \times 1.5 \mathrm{~mm}$; two acquisitions].

\section{Image Processing}

Image pre-processing and statistical analysis were performed using SPM8 (Wellcome Trust Centre for Neuroimaging, UCL, London, UK; http://www.fil.ion.ucl.ac.uk/spm) running under MatLab 7.14 (Mathworks, Sherborn, MA, USA). MR images were processed using Diffeomorphic Anatomical RegisTration using Exponentiated Lie algebra (DARTEL) (Ashburner, 2007) with standard parameters for VBM. All analyses were performed on bias-corrected, segmented, registered (rigid-body transformation), interpolated isotropic $(1.5 \times 1.5 \times 1.5 \mathrm{~mm})$, and smoothed (FWHM $8 \mathrm{~mm}$ ) images. All images were warped based on the transformation of the standard MNI152 DARTEL template to the GM prior image provided by SPM8 to meet the standard stereotactical space of the Montreal Neurological Institute (MNI). GM segments were non-linearly scaled by the Jacobian determinants of the deformations introduced by normalization to account for local compression and expansion during transformation.

\section{Data Analysis Behavioral Data}

All analyses were performed with PASW-SPSS-Statistics 22.0 (IBM Corporation, Somers, NY, USA). A possible group-related difference with respect to subjects' VAS ratings of hunger was assessed by ANOVA. Differences in nine-point Likert scale liking and wanting ratings of individual food reward items that entered the task were assessed by Mann-Whitney U-tests. Post-hoc pairwise comparisons were computed with two sample $T$-tests or Mann-Whitney U-tests and adjusted for pairwise comparisons.

We applied a generalized estimating equations (GEE) approach to assess the impact of our variables of interest on subjects' reaction times and on subjects' single trial binary decisions. GEE is an extension of a generalized linear model that is capable of accounting for possible unknown correlations between residuals. An advantage of GEE is that its parameter estimates are consistent under mild regularity conditions, even when the covariance structure is mis-specified (Zeger and Liang, 1986). Computed GEE models utilized a first order autoregressive working correlation matrix, a linear normal outcome distribution for modeling reaction times and a binary logistic outcome distribution to model subjects' decisions to grip or not on each single trial, respectively.

We computed four successive GEE models for both reaction times and choice analysis, respectively. The first model contained as predictor variables trial block, trial order (reward first/effort first), reward category, reward and effort magnitude, and the interaction of the two latter. Based on our hypotheses we included obesity, gender, subjects' reward and punishment sensitivity, and perceived chronic stress as further predictors. To control for individual differences in wanting and possible effects of age, we included subjects' wanting ratings of the food items, and age as covariates. For analysis purposes, we set wanting ratings constantly to the highest value (9) for monetary reward, assuming that every participant wanted to receive money. As we wished to assess whether reaction times differed with respect to subjects' choices (yes/no), we also included the binary decision for each single trial and a three-way interaction term of effort magnitude, reward magnitude, and decision into the first GEE for reaction time analysis.

Covariates that yielded no statistical significance in the first GEE model, at least on a trend level $(p<0.1)$, were disregarded in subsequent GEE models. In the second GEE, we tested for obesity- and gender-specific two-way interactions, i.e., gender by effort magnitude, gender by reward category, obesity by effort level, obesity by reward category, and obesity by gender. The second model for choice analysis also included the interactions of obesity by trial block and gender by trial block to assess grouprelated differences over time. According to our hypotheses, the third GEE was set up to assess a three-way interaction of reward category, obesity, and gender. To test for a modulatory effect of body dissatisfaction, we assessed a four-way interaction between reward category, obesity, gender, and body dissatisfaction with the last GEE model.

Age, reward sensitivity, punishment sensitivity, chronic stress, and individual wanting ratings were mean centered prior to analyses. Self-reported body dissatisfaction was centered on the 
respective group mean with regard to gender and obesity, as we were interested in its impact specifically for each group.

Post-hoc analyses of interaction effects were based on estimated marginal means (EMMs) of the mean response for reaction time analyses and on EMMs of the linear predictor of the binary outcome variable "decision" and consisted of Wald ChiSquare Tests and ANOVAs for pairwise comparisons, corrected for multiple comparisons utilizing Bonferroni correction.

\section{Structural MRI Data}

We utilized a full-factorial design within SPM8 running under Matlab 7.14 with factors obesity and gender, and fraction of yes decisions, wanting ratings (averaged over all sweet snack and fruit items), and implicit food craving (differences in hunger ratings post-pre) as covariates. Age and total intracranial volume were included to account for the confounding effects of age and individual brain size. We assessed obesity-related gray matter volume differences on a whole-brain level. According to our specific hypothesis of an association between NAcc volume and willingness to exert effort (fraction of yes decisions), as well as between NAcc volume and measures of food craving (wanting ratings and task induced implicit food craving), we utilized a ROI-based approach with a NAcc mask obtained from the Harvard-Oxford Subcortical Structural Atlas within FSL 4.1 to test for related effects. Family-wise Error (FWE) correction for multiple comparisons was applied at the cluster level with a statistical threshold of $p<0.05$.

\section{RESULTS}

\section{Demographics, Ratings, and Questionnaires}

Statistical assessment of demographic, rating, and questionnaire data as well as subjects' maximum hand grip forces, mean reaction times and fraction of decisions to exert effort over the whole task are summarized in Table 1. Subject groups did not differ with respect to age and educational background, depressive symptoms, reward or punishment sensitivity, and chronic stress levels. Self-reported body dissatisfaction differed significantly between groups $\left[F_{(3,56)}=22.62, p<0.001\right]$. Post-hoc T-Test revealed that lean men reported lower body dissatisfaction than obese men $\left[T_{(26)}=-7.16, p<0.001\right]$ and lean women reported lower body dissatisfaction than obese women $\left[T_{(27)}=-4.10\right.$, $p<0.001]$. Further, lean men reported lower body dissatisfaction than lean women $\left[T_{(26)}=-4.46, p<0.001\right]$.

Participants did not significantly differ with respect to hunger prior to task or task-induced implicit food craving (see Table 1). While we found no differences with respect to self-reported liking of the fruit items that entered the task, subjects differed with respect to liking of the sweet snack items $\left[H_{(3)}=8.13, p<\right.$ 0.05]. Post-hoc analysis revealed that lean women showed higher liking of sweet snack items than obese men $\left[H_{(2)}=16.6, p<\right.$ $0.01]$. All other pairwise comparisons did not survive correction for multiple comparisons. Importantly, all four subject groups showed comparable wanting ratings of the individual sweet snack and fruit items that entered the task (see Table 1).
Maximum hand grip force assessed prior to the task differed between subject groups $\left[F_{(3,56)}=34.96, p<0.001\right.$, Table 1]. Post-hoc T-Tests revealed that this was related to gender differences. Both lean and obese men showed higher hand grip force compared with lean women [obese men: $T_{(28)}=7.59$, $p<0.001$; lean men: $\left.T_{(26)}=6.80, p<0.001\right]$ and obese women [obese men: $T_{(27)}=7.35, p<0.001$; lean men: $T_{(25)}=6.56$, $p<0.001]$. In the subsequent task, effort levels were adjusted to individual maximum hand grip force.

\section{Reaction Time and Cost-Benefit Decisions Task-Design}

Subjects carefully evaluated the tradeoff between costs and benefits. This was reflected in subjects' reaction times by a threeway interaction of effort magnitude, reward magnitude, and fraction of decisions to exert effort $\left(\mathrm{X}^{2}=42.46, p<0.001\right.$, Figure 1E). Subjects decided fastest to grip in trials involving low effort (le) and high reward (hr) levels and were slowest in accepting cost-benefit offers in trials with high effort (he) and low reward $(\mathrm{lr})$ magnitude $[\mathrm{EMM}(\mathrm{le} / \mathrm{hr})=578.61 \mathrm{~ms}, \mathrm{EMM}(\mathrm{he} / \mathrm{lr})=$ $621.68 \mathrm{~ms}, p<0.001]$. For deciding to reject cost-benefit offers the opposite pattern was observable $[\mathrm{EMM}(\mathrm{le} / \mathrm{hr})=737.18 \mathrm{~ms}$, $\operatorname{EMM}($ he/lr $)=626.26 \mathrm{~ms}, p<0.001]$. This was mirrored in subjects' decisions, i.e., they more often chose to grip in low compared with high effort trials $\left(\mathrm{X}^{2}=200.74, b=1.56\right.$, $p<0.001$, Figure 1C) and in high compared with low reward trials $\left(\mathrm{X}^{2}=160.44, b=2.33, p<0.001\right.$, Figure 1C). As expected, individual wanting ratings of included reward items correlated positively with the amount of exerted effort $\left(X^{2}=\right.$ $17.15, b=0.29, p<0.001)$ and subjects' willingness to invest effort to receive rewards decreased over time $\left(X^{2}=67.17, p<\right.$ 0.001 , Figure 1B). Comparing reward categories, we observed that subjects significantly faster decided in trials that yielded money than fruit items $\left(X^{2}=5.68, b=-17.6, p<0.05\right)$. Subjects also more often chose to grip for money than for sweet snacks $\left(X^{2}=16.47, b=1.14, p<0.001\right.$, Figure 1D) or fruit pieces $\left(X^{2}=5.1, b=0.72, p<0.05\right.$, Figure $\left.1 D\right)$.

Whether reward or effort demand was depicted first also influenced subjects' task performance. They decided faster whether to grip or not in trials in which reward stimuli were displayed before effort demands were shown $\left(\mathrm{X}^{2}=41.69, b\right.$ $=-29.63, p<0.001)$. In these trials, subjects were also more likely to invest effort than in trials, in which effort levels were shown first $\left(X^{2}=6.97, b=0.1, p<0.01\right)$. Taken together, these results support the ecological validity of our approach.

\section{Obesity- and Gender-Related Effects}

Throughout the task, lean subjects responded faster than obese participants $\left(X^{2}=4.67, b=-44.05, p<0.05\right.$, Table 1). We found no association of obesity and general amount of exerted effort throughout the task (Table 1). However, we observed a significant obesity by gender interaction $\left(X^{2}=5.12, p<0.05\right)$ : Obese men less likely invested effort than lean men $[\mathrm{EMM}(\mathrm{lm})=$ $0.81, \operatorname{EMM}(\mathrm{om})=0.63, p<0.01$, Table 1]. This obesity-related difference was not observable in women $[\operatorname{EMM}(\mathrm{lw})=0.71$, $\operatorname{EMM}($ ow $)=0.75, p=0.59]$. 
As hypothesized, our data showed an obesity by reward category interaction $\left(X^{2}=7.92, p<0.05\right.$, Figure 2): Obese compared with lean subjects were less likely to grip on trials yielding sweet snacks $[\operatorname{EMM}(1)=0.71, \operatorname{EMM}(\mathrm{o})=0.5, p<0.05]$ but not on trials involving fruit pieces or money as a reward. Obese subjects more often decided to grip for money and for fruits than for sweet snacks $[\operatorname{EMM}(\mathrm{mo})=0.85, \operatorname{EMM}(\mathrm{sw})=0.5$, $p<0.001 ; \operatorname{EMM}(\mathrm{fr})=0.66, p<0.01]$. Lean subjects equally often decided to grip regarding the three reward categories.

Reaction time analysis further revealed a significant interaction of gender by reward category $\left(X^{2}=9.05, p<0.05\right.$, Figure 1F). Men decided faster in trials that yielded monetary reward (mo) compared to fruit (fr) and sweet snack (sw) trials $[\operatorname{EMM}(\mathrm{mo})=590.21 \mathrm{~ms}, \operatorname{EMM}(\mathrm{fr})=631.38, p<0.01$; $\operatorname{EMM}(\mathrm{sw})=625.79, p<0.01]$, but no such differentiation was found in women. With respect to subjects' decisions, we found a significant effort level by gender interaction $\left[X^{2}=5.32\right.$, $p<0.05]$. Specifically, women were more sensitive to an increase in effort demands than men, i.e., women were more likely to invest effort in low effort trials than men, but men more often decided to exert effort in high effort trials than women [low effort: $\operatorname{EMM}(\mathrm{w})=0.88, \operatorname{EMM}(\mathrm{m})=0.85$; high effort: $\left.\operatorname{EMM}(\mathrm{w})=0.51, \operatorname{EMM}(\mathrm{m})=0.56 ; X^{2}=186.86, p<0.001\right]$. We did not find significant interactions of trial block by obesity, trial block by gender or obesity by gender and reward category.

\section{Influence of Age, Chronic Stress, Reward/Punishment Sensitivity, and Body Dissatisfaction}

Across all subjects, reaction times marginally increased $\left(X^{2}=\right.$ $3.53, b=3.02, p<0.06)$ and subjects' amount of expended effort decreased with increasing chronic stress $\left(X^{2}=5.47, b=-0.03\right.$, $p<0.05$, Figure 3A). Further, subjects' punishment sensitivity correlated negatively $\left(X^{2}=11.34, b=-0.14, p<0.001\right.$, Figure 3B) with the fraction of decisions to invest effort. Age

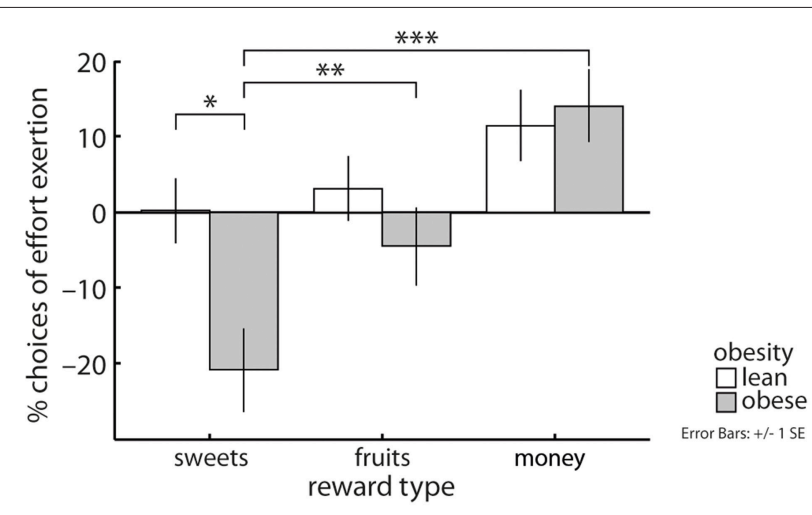

FIGURE 2 | An interaction between reward category and obesity revealed that obese compared with lean subjects less often chose to grip for sweet high-caloric snacks, but performed similarly with respect to fruits and money as rewards. Obese subjects also more often decided to grip for money and for fruits than for sweets, this effect was not apparent in lean subjects. Depicted values are corrected for factors and covariates within the respective GEE model. Asterisks indicate significance within the respective GEE model reported in the Results Section. and reward sensitivity had no significant impact on subjects' decisions, though with increasing age reaction times increased $\left(X^{2}=6.03, b=7.57, p<0.05\right)$.

Following our hypothesis, we finally investigated if body dissatisfaction had an impact on cost-benefit decisions. We assessed a four-way interaction of reward category, obesity, gender, and reported body dissatisfaction. This interaction was significant $\left(X^{2}=37.33, p<0.001\right.$, Figures 4A-D). However, contrary to our hypothesis, parameter estimates of the model showed that body dissatisfaction negatively correlated with the likelihood to grip for sweet snacks in obese men $\left(X^{2}=5.48\right.$, $b=-0.05, p<0.05$, Figure 4A), but not in obese women $\left(X^{2}=1.44, b=0.05, p=0.23\right.$, Figure 4B).

\section{Structural MRI}

On a whole-brain level, obese compared with lean subjects had lower gray matter volume in bilateral clusters of ventrolateral $\mathrm{PFC}$, comprising inferior frontal gyrus (Table 2, Figure 5A). We found no positive association of obesity and gray matter volume.

ROI analysis of NAcc gray matter volume yielded a significant positive correlation of implicit food craving and bilateral NAcc volume (Table 2, Figures 5B,C). We found no significant association of NAcc volume and subjects' willingness to exert effort, or explicit wanting ratings.

\section{DISCUSSION}

Here we show that the trade-off between costs in terms of physical effort and food reward in obese subjects may be more complex than expected up to date (Epstein et al., 2007; Giesen et al., 2010). Our data demonstrate for the first time that obese compared with lean subjects may be less willing to invest physical effort for high-caloric food reward in particular. Importantly, in a recent study that utilized button presses to obtain a reward, we observed that obese men were less sensitive to changes in motivational value of snack food, as induced via a devaluation procedure, than lean men (Horstmann et al., 2015a). This indicates that the obesity-related difference observed here is specific for physical effort, emphasizing the importance of taking into account physical effort as a potential target for therapeutic interventions and changing every day food choices of obese subjects possibly via increasing effort barriers, e.g., by rearrangement of food assortments in cafeterias and supermarkets. Two recent studies in humans (Epstein et al., 2007; Giesen et al., 2010) revealed contradictory results to our finding, which most likely reflects methodological differences. We used three distinct reward categories and, in contrast to previous studies that employed button presses, assessed physical effort via a handgrip dynamometer which has proven to be a reliable tool to capture physical exertion (e.g., Treadway et al., 2009; Wardle et al., 2012). Notably, findings in rodents related to cost-benefit decision-making alterations in obesity models are also diverse. While some studies show an increased motivation to work for high-caloric sweet food in rodent models of obesity (la Fleur et al., 2007; Hajnal et al., 2008; Narayanaswami et al., 2013), there is also growing evidence for a decreased willingness to exert effort for food high in fat and 

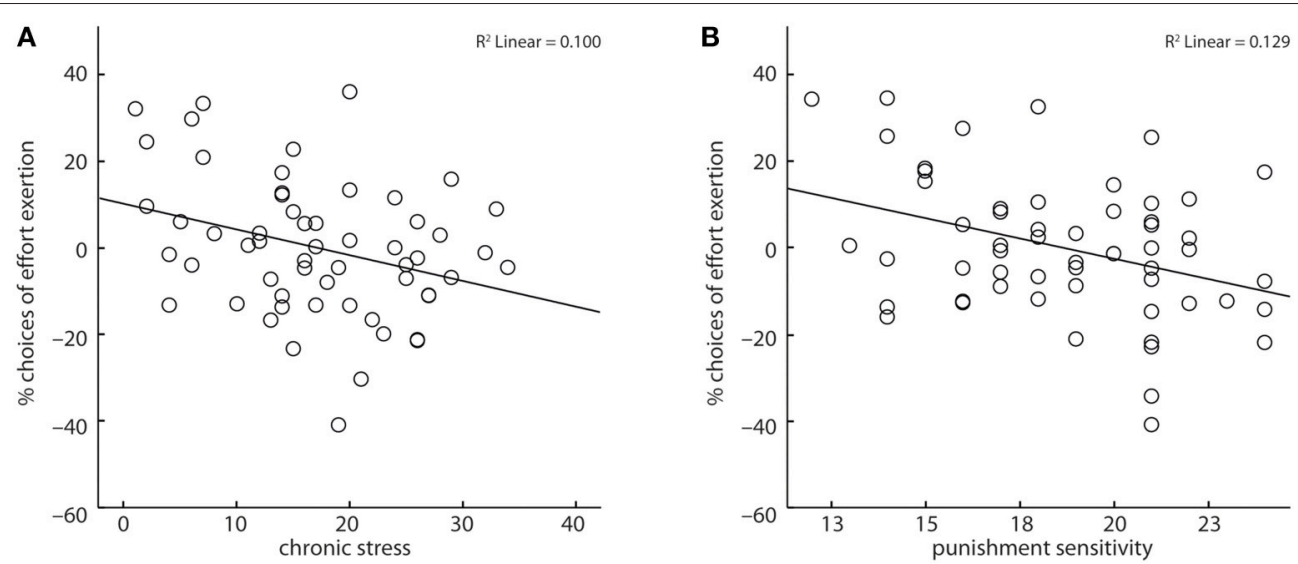

FIGURE 3 | Chronic stress (A) and punishment sensitivity (B) correlated negatively with the likelihood of choosing to exert effort. Depicted values are corrected for factors and covariates within the respective GEE model.
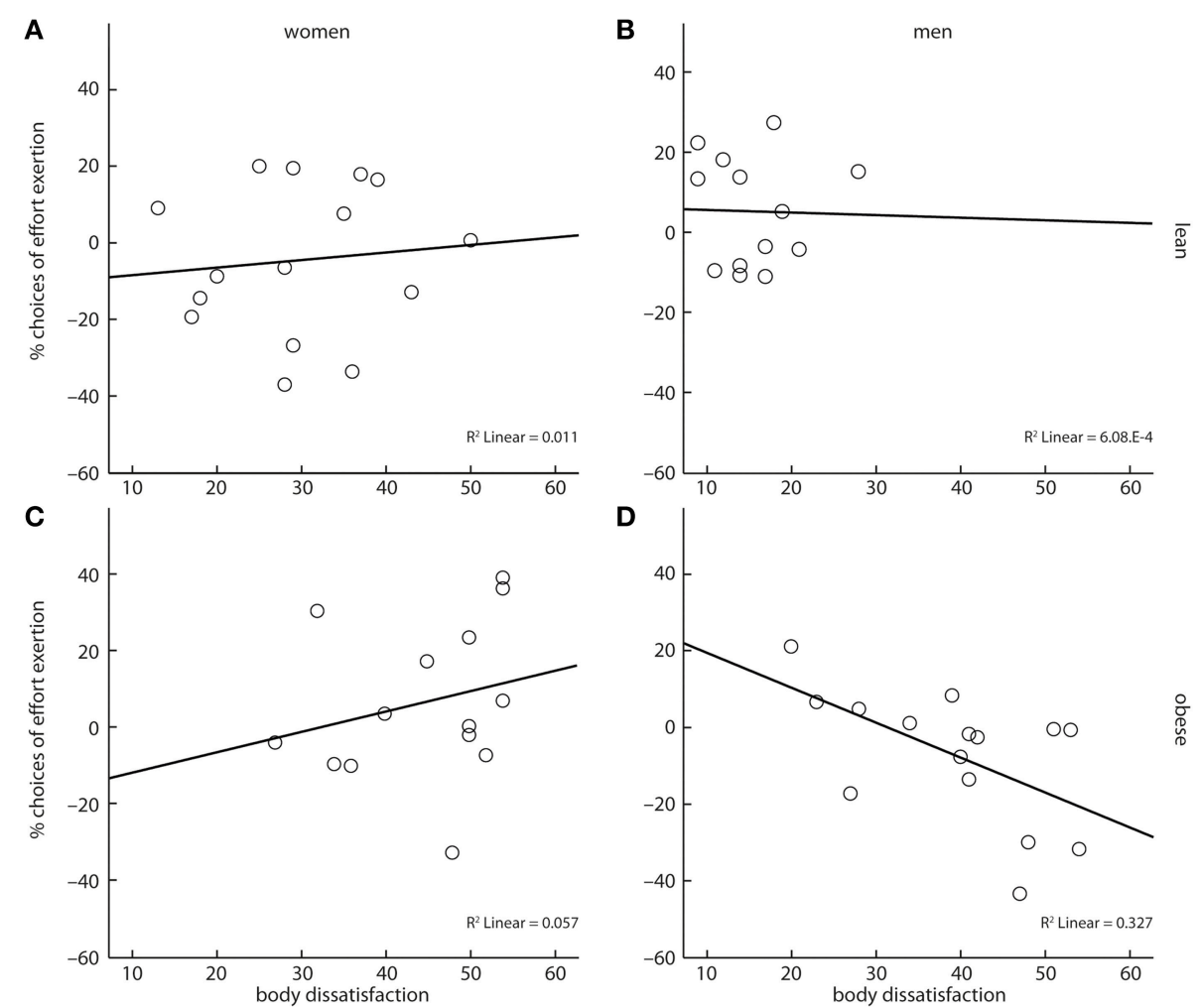

FIGURE 4 | A four-way interaction between reward category, obesity, gender, and body dissatisfaction showed that obese men's cost-benefit decisions regarding sweet snacks were negatively correlated with their self-reported body dissatisfaction (D). No such association was observed for lean women (A), lean men (B), and obese women (C). Depicted values are corrected for factors and covariates within the respective GEE model. Asterisks depict significance within the GEE model.

sugar (Davis et al., 2008; Shin et al., 2011; Harb and Almeida, 2014). This reduced motivation to work for food reward may partly be associated with an attenuated dopamine metabolism, possibly reflecting adaptive processes such as heightened DA level within NAcc as a result from a prolonged energy-dense diet (Davis et al., 2008). Studies in humans show reduced striatal
D2/D3 receptor availability in obese compared with lean subjects that may relate to heightened tonic DA as well (Horstmann et al., 2015b). Following this, our findings may hint at similar associations between disturbances in dopaminergic function and reduced motivation to exert effort for high-caloric food in obese individuals. 
The observed obesity-associated difference in cost-benefit evaluation was modulated by self-reported body dissatisfaction and gender. In obese men, but not in obese women, the likelihood of choosing to invest physical effort for high-caloric sweet snacks was negatively correlated with body image discontent. We expected to observe an impact of body dissatisfaction on cost-benefit decisions rather in obese women than in obese men, due to the supposed greater burden of stigmatization in obese women (Gray et al., 2011; Forrester-Knauss and Zemp Stutz, 2012; Forste and Moore, 2012). Our opposing observation hints at a greater awareness and impact of weight discrimination on behavior in men than expected to date. In accordance, Lieberman et al. (2012) recently reported that men showed greater negative attitudes toward obesity than women. Further, they found that BMI positively correlated with the strength of negative attitudes toward obesity in men but not in women. The higher the BMI of their male participants was, the more they were concerned with the fear of getting obese. In addition, frequency of consuming fast-food is higher in men than in women and correlates positively with BMI (Dave et al., 2009; Anderson et al., 2011). A prolonged period of consuming convenience products may foster the association between palatable food and low effort demands. Further, prolonged consumption of

TABLE 2 | Results from the VBM analysis in a subsample of 42 subjects.

\begin{tabular}{lccc}
\hline & $\begin{array}{c}\text { MNI-coordinates } \\
\text { (peak voxel) }\end{array}$ & $\begin{array}{c}\text { Number } \\
\text { of voxels }\end{array}$ & Z-Score \\
\hline LEAN > OBESE SUBJECTS & (WHOLE-BRAIN) & & \\
\hline Right inferior frontal gyrus & $54,39,9$ & 1134 & 4.43 \\
Left inferior frontal gyrus & $-50,30,18$ & 2091 & 4.73 \\
IMPLICIT FOOD CRAVING (ROI-BASED) & & \\
Right NAcc & $10,15,-11$ & 158 & 3.64 \\
Left NAcC & $-3,14,-2$ & 30 & 3.63 \\
\hline
\end{tabular}

Lean (23) compared with obese subjects had higher gray matter volume in bilateral inferior frontal gyrus. NAcc volume correlated positively with implicit food craving severity. palatable food can lead to a decrease in liking of these food items (Clark et al., 2010).

The modulating effect of gender on the observed obesityassociated differences in cost-benefit evaluation may also be related to differences in dopaminergic tone within the frontostriatal pathway (e.g., Haaxma et al., 2007). Estrogen level was shown to impact measures of dopamine-related cognitive performance and inhibitory control (Colzato et al., 2010; Jacobs and D’Esposito, 2011; Silverman et al., 2011; Hampson and Morley, 2013). In rodents, modification of estradiol levels was previously related to alterations in cost-benefit decision-making (Uban et al., 2012).

Subjects choose to invest effort to receive a certain reward if their subjective motivational value of the reward item exceeds the respective effort costs. Accordingly, individual wanting ratings correlated positively with subjects' choices. Notably, we also tested whether controlling for liking of the food items would change our obesity-associated results. This was not the case. Thus, behavior in our task was driven by the current motivational value of the rewards. Literature on obesityassociated differences with respect to wanting and liking of sweet snack food is still inconsistent. Despite studies showing a positive relationship between the reinforcing value of snack food and body weight (Ouwehand and de Ridder, 2008; Goldfield et al., 2011; Ochner et al., 2012), there is also evidence of a possible negative association (Cox et al., 1998; Gearhardt et al., 2014). Consumption of high-caloric food over a prolonged period can decrease liking of energy-dense food (Clark et al., 2010; Vucetic et al., 2011).

Women were more sensitive to increases in physical effort demands than men. This is in accordance with previous findings, indicating that men rated perceived exertion lower than women (Skatrud-Mickelson et al., 2011). A possible contribution to this gender-associated difference may arise from motivation intensity theory, indicating that men are more likely to be motivated by performance incentives (Barreto et al., 2012). Further, Perciavalle et al. (2010) showed that motor cortex in women is more sensitive to increases in circulating blood lactate levels than men's motor
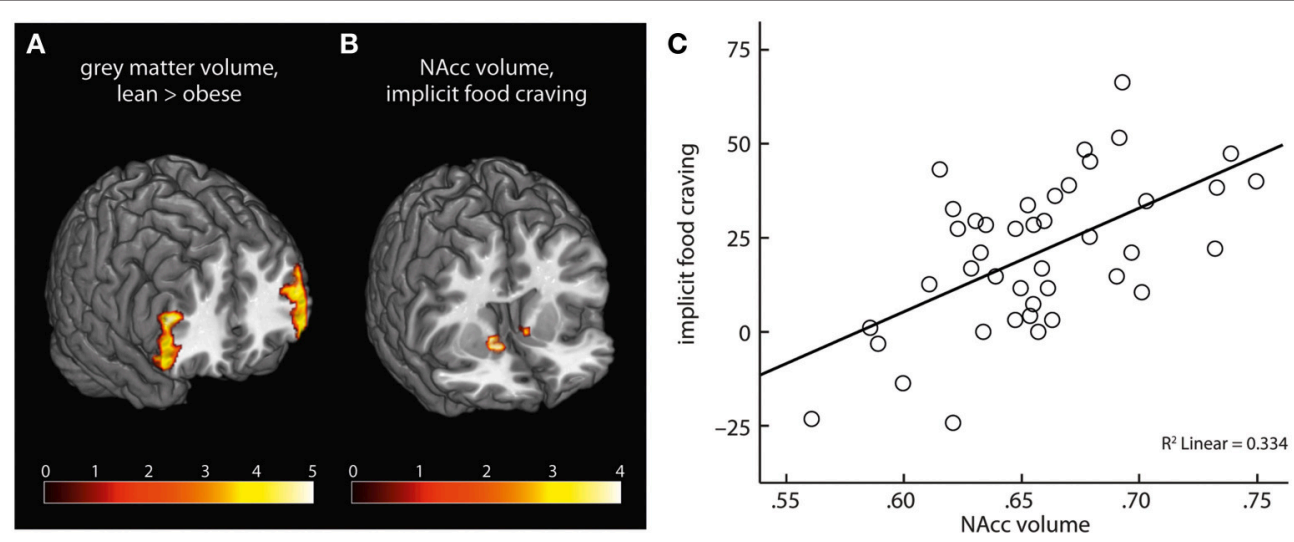

FIGURE 5 | Obese subjects had lower gray matter volume in bilateral PFC compared with lean participants (A). NAcc volume positively correlated with severity of implicit food craving (B,C). 
cortex, hinting at sensitivity differences of physical exertion on a neural level.

Subjects' punishment sensitivity negatively correlated with their willingness to exert effort. This indicates that in our task design, effort exertion via pressing a handgrip device was perceived as physically demanding by the participants. This is an important aspect regarding the comparability with studies that used button presses as a measure of effort costs and that reported different results with respect to obesity (e.g., Giesen et al., 2010). Punishment sensitivity is associated with dopaminergic tone, specifically within the right frontal cortex and striatum (e.g., Maril et al., 2013). On a neural level, individual tonic dopamine level differences within the right fronto-striatal pathway may thus have contributed to sensitivity differences with respect to effort demands in our task.

Notably, self-reported chronic stress levels were negatively associated with subjects' likelihood of choosing to grip for rewards. This novel finding in humans is in accordance with a recent observation in rodents (Shafiei et al., 2012) that acute stress diminished the preference of rats to exert high effort levels to receive rewards. Stress is known to affect dopaminergic transmission within the fronto-striatal circuitry (Roth et al., 1988; Abercrombie et al., 1989; Davis et al., 1994; Latagliata et al., 2014). Since the same dopaminergic pathways are involved in processing effort-related information during costbenefit decision-making (Walton et al., 2003; Schweimer and Hauber, 2006; Salamone et al., 2007; Salamone and Correa, 2012), stress may alter cost-benefit decision-making via modifying dopamine transmission in fronto-striatal dopaminergic target regions.

With respect to brain structure, we found lower gray matter volume in bilateral PFC comprising large parts of inferior frontal gyrus in obese compared with lean participants in a subsample of 42 participants. IFG is involved in inhibitory control mechanisms to guide behavior in a goal-directed manner among a variety of other processes (e.g., Aron et al., 2004; Swann et al., 2009). Hypo-functioning and lower gray matter volume within IFG have been related to obesity and disordered eating before (Batterink et al., 2010; Sweet et al., 2012; Balodis et al., 2013; Brooks et al., 2013). Regarding the motivation to overcome physical effort, Treadway et al. (2012) found that dopamine responsivity within IFG among other regions positively predicted willingness to exert effort in trials entailing high effort demands but low reward probabilities. In line, Massar et al. (2015) recently showed that IFG is critical for coding effortful demands. In contrast to our recent findings (Horstmann et al., 2011), we did not observe a positive association of obesity and gray matter volume in reward related areas or a modulatory effect of gender on gray matter volumetric differences regarding obesity. This may be related to the relatively small sample size compared with the former study.

As hypothesized, gray matter volume of NAcc positively correlated with an implicit measure of task-induced craving for food, as assessed by differences in subjects' hunger ratings before and after task execution. This is in line with recent findings that showed NAcc activity to correlate with craving severity in smokers (Kober et al., 2010). As we only assessed brain structure in this study, the next crucial step is to assess brain function during cost-benefit decision-making, to follow up on this finding. Associations between local gray matter volume and BOLD activation are complex, and dependent on the specific region of interest and the respective task among a multitude of other factors. Besides no direct associations (Guo et al., 2015) there are also studies showing a positive (Kalpouzos et al., 2012; Pujol et al., 2013) but also a negative correlation between local gray matter volume and BOLD response (Johnson et al., 2000; Bartrés-Faz et al., 2009; Kalpouzos et al., 2012).

Subjects' reaction times were modulated by reward and effort magnitude in a differential manner for yes and no decisions. Thus, subjects carefully evaluated reward and effort information and integrated both to form a decision. In line with this observation, Basten et al. (2010) recently proposed that costbenefit decisions were established in an analogous way to perceptual decisions, i.e., the brain weighs costs and benefits by accumulating the difference signal of both on a neural level until a decision threshold is reached. Further, participants with obesity responded slower throughout the task than lean subjects. This is a common finding with respect to both simple (e.g., Khode et al., 2012; Gentier et al., 2013; Hagger-Johnson et al., 2014) and cognitive more demanding tasks (e.g., Nederkoorn et al., 2012; Gentier et al., 2013; Kamijo et al., 2014). In addition, men decided faster in trials involving monetary compared to food reward. This is congruent with recent observations that men but not women responded faster in a reaction time task involving monetary compared with social reward and that men revealed a differential BOLD activation pattern during anticipation of the distinct reward types (Spreckelmeyer et al., 2009).

In conclusion, our novel findings shed new light on obesityrelated alterations in cost-benefit decision-making. Former findings that obese individuals may be willing to work harder for high-caloric food are challenged. Moreover, obese men seem to be more affected by concerns about body shape and possibly by related stigmatization than previously expected. This is an important issue for therapeutic strategies aiming at weight reduction and reducing stigmata in obese men. Further, increasing effort barriers for high-caloric food in food and eating environments (e.g., cafeterias, supermarkets), for example, by repositioning food assortments, may prove as a powerful tool to influence eating behavior. Additionally, therapeutic interventions aiming at altering psycho-social burdens such as stress may help to positively influence everyday-life effortful decisions and thereby reduce positive energy-balances in obese individuals.

\section{AUTHOR CONTRIBUTIONS}

$\mathrm{DM}, \mathrm{AH}, \mathrm{BP}, \mathrm{AV}$, and $\mathrm{JN}$ conceived and designed the experiment, $\mathrm{DM}$ acquired data, DM, AH, JN performed data analysis. DM, $\mathrm{AH}, \mathrm{BP}, \mathrm{AV}$, and JN prepared and revised the manuscript. JN supervised the study. 


\section{FUNDING}

This work was supported by the Federal Ministry of Education and Research (BMBF), Germany (FKZ: 01EO1001), the German Research Foundation (DFG-SFB1052), the FAZIT-STIFTUNG (FAZIT-STIFTUNG Gemeinnützige Verlagsgesellschaft $\mathrm{mbH}$ ), and the Free State of Saxony (Landesstipendium).

\section{REFERENCES}

Abercrombie, E. D., Keefe, K. A., DiFrischia, D. S., and Zigmond, M. J. (1989). Differential effect of stress on in vivo dopamine release in striatum, nucleus accumbens, and medial frontal cortex. J. Neurochem. 52, 1655-1658. doi: 10.1111/j.1471-4159.1989.tb09224.x

Anderson, B., Rafferty, A. P., Lyon-Callo, S., Fussman, C., and Imes, G. (2011). Prev Fast-food consumption and obesity among Michigan adults. Prev. Chronic Dis. 8, A71.

Aron, A. R., Robbins, T. W., and Poldrack, R. A. (2004). Inhibition and the right inferior frontal cortex. Trends Cogn. Sci. 8, 170-177. doi: 10.1016/j.tics.2004.02.010

Ashburner, J. (2007). A fast diffeomorphic image registration algorithm. Neuroimage 38, 95-113. doi: 10.1016/j.neuroimage.2007.07.007

Balodis, I. M., Molina, N. D., Kober, H., Worhunsky, P. D., White, M. A., Rajita Sinha, et al. (2013). Divergent neural substrates of inhibitory control in binge eating disorder relative to other manifestations of obesity. Obesity 21, 367-377. doi: 10.1002/oby.20068

Barreto, P., Wong, J., Estes, K., and Wright, R. A. (2012). Gender determination of effort and associated cardiovascular responses: when men place greater value on available performance incentives. Psychophysiology 49, 683-689. doi: 10.1111/j.1469-8986.2011.01342.x

Bartrés-Faz, D., Solé-Padullés, C., Junqué, C., Rami, L., Bosch, B., Bargalló, N., et al. (2009). Interactions of cognitive reserve with regional brain anatomy and brain function during a working memory task in healthy elders. Biol. Psychol. 80, 256-259. doi: 10.1016/j.biopsycho.2008.10.005

Basten, U., Biele, G., Heekeren, H. R., and Fiebach, C. J. (2010). How the brain integrates costs and benefits during decision making. Proc. Natl. Acad. Sci. U.S.A. 107, 21767-21772. doi: 10.1073/pnas.0908104107

Batterink, L., Yokum, S., and Stice, E. (2010). Body mass correlates inversely with inhibitory control in response to food among adolescent girls: an fMRI study. Neuroimage 52, 1696-1703. doi: 10.1016/j.neuroimage.2010.05.059

Bautista, L. M., Tinbergen, J., and Kacelnik, A. (2001). To walk or to fly? How birds choose among foraging modes. PNAS 98, 1089-1094. doi: 10.1073/pnas.98.3.1089

Beck, A. T., Steer, R. A., Ball, R., and Ranieri, W. (1996). Comparison of Beck Depression Inventories-IA and -II in psychiatric outpatients. J. Pers. Assess. 67, 588-597. doi: 10.1207/s15327752jpa6703_13

Belujon, P., and Grace, A. A. (2011). Hippocampus, amygdala, and stress: interacting systems that affect susceptibility to addiction. Ann. N. Y. Acad. Sci. 1216, 114-121. doi: 10.1111/j.1749-6632.2010.05896.x

Brooks, S. J., Benedict, C., Burgos, J., Kempton, M. J., Kullberg, J., Nordenskjöld, R. B., et al. (2013). Late-life obesity is associated with smaller global and regional gray matter volumes: a voxel-based morphometric study. Int. J. Obes. 37, 230-236. doi: 10.1038/ijo.2012.13

Carver, C. S., and White, T. L. (1994). Behavioral inhibition, behavioral activation, and affective responses to impending reward and punishment: the BIS/BAS Scales. J. Pers. Soc. Psychol. 67, 319-333. doi: 10.1037/0022-3514. 67.2.319

Clark, E. N., Dewey, A. M., and Temple, J. L. (2010). Effects of daily snack food intake on food reinforcement depend on body mass index and energy density. Am. J. Clin. Nutr. 91, 300-308. doi: 10.3945/ajcn.2009.28632

Colzato, L. S., Hertsig, G., van den Wildenberg, W. P., and Hommel, B. (2010). Estrogen modulates inhibitory control in healthy human females: evidence from the stop-signal paradigm. Neuroscience 19, 709-715. doi: 10.1016/j.neuroscience.2010.02.029

\section{ACKNOWLEDGMENTS}

We wish to thank Martin Federbusch, Jakob Simmank, and Haiko Schlögl for medical support, Ramona Menger for helping to recruit subjects, and Bettina Johst for technical advice regarding the presentation software.

Cox, D. N, van Galen, M., Hedderley, D., Perry, L., Moore, P. B., and Mela, D. J. (1998). Sensory and hedonic judgments of common foods by lean consumers and consumers with obesity. Obes. Res. 6, 438-447. doi: 10.1002/j.15508528.1998.tb00376.x

Croxson, P. L., Walton, M. E., O'Reilly, J. X., Behrens, T. E., and Rushworth, M. F. (2009). Effort-based cost-benefit valuation and the human brain. J. Neurosci. 29, 4531-4541. doi: 10.1523/JNEUROSCI.4515-08.2009

Dave, J. M., An, L. C., Jeffery, R. W., and Ahluwalia, J. S. (2009). Relationship of attitudes toward fast food and frequency of fast-food intake in adults. Obesity 17, 1164-1170. doi: 10.1038/oby.2009.26

Davis, J. F., Tracy, A. L., Schurdak, J. D., Tschöp, M. H., Lipton, J. W., Clegg, D. J., et al. (2008). Exposure to elevated levels of dietary fat attenuates psychostimulant reward and mesolimbic dopamine turnover in the rat. Behav. Neurosci. 122, 1257-1263. doi: 10.1037/a0013111

Davis, M., Hitchcock, J. M., Bowers, M. B., Berridge, C. W., Melia, K. R., and Roth, R. H. (1994). Stress-induced activation of prefrontal cortex dopamine turnover: blockade by lesions of the amygdala. Brain Res. 664, 207-210. doi: 10.1016/0006-8993(94)91972-0

de Weijer, B. A., van de Giessen, E., van Amelsvoort, T. A., Boot, E., Braak, B., Janssen, I. M., et al. (2011). Lower striatal dopamine D2/3 receptor availability in obese compared with non-obese subjects. EJNMMI Res. 1:37. doi: 10.1186/2191-219X-1-37

Dietrich, A., Federbusch, M., Grellmann, C., Villringer, A., and Horstmann, A. (2014). Body weight status, eating behavior, sensitivity to reward/punishment, and gender: relationships and interdependencies. Front. Psychol. 5:1073. doi: 10.3389/fpsyg.2014.01073

Epstein, L. H., Temple, J. L., Neaderhiser, B. J., Salis, R. J., Erbe, R. W., and Leddy, J. J. (2007). Food reinforcement, the dopamine D2 receptor genotype, and energy intake in obese and nonobese humans. Behav. Neurosci. 121, 877-886. doi: 10.1037/0735-7044.121.5.877

Forrester-Knauss, C., and Zemp Stutz, E. (2012). Gender differences in disordered eating and weight dissatisfaction in Swiss adults: which factors matter? BMC Public Health 12:809. doi: 10.1186/1471-2458-12-809

Forste, R., and Moore, E. (2012). Adolescent obesity and life satisfaction: perceptions of self, peers, family, and school. Econ. Hum. Biol. 10, 385-394. doi: 10.1016/j.ehb.2012.04.008

Gearhardt, A. N., Rizk, M. T., and Treat, T. A. (2014). The association of food characteristics and individual differences with ratings of craving and liking. Appetite 79, 166-173. doi: 10.1016/j.appet.2014.04.013

Gentier, I., Augustijn, M., Deforche, B., Tanghe, A., De Bourdeaudhuij, I., Lenoir, M., et al. (2013). A comparative study of performance in simple and choice reaction time tasks between obese and healthy-weight children. Res. Dev. Disabil. 34, 2635-2641. doi: 10.1016/j.ridd.2013.04.016

Giesen, J. C., Havermans, R. C., Douven, A., Tekelenburg, M., and Jansen, A. (2010). Will work for snack food: the association of BMI and snack reinforcement. Obesity 18, 966-970. doi: 10.1038/oby.2010.20

Goldfield, G. S., Lumb, A. B., and Colapinto, C. K. (2011). Relative reinforcing value of energy-dense snack foods in overweight and obese adults. Can. J. Diet. Pract. Res. 72, 170-174. doi: 10.3148/72.4.2011.170

Gray, W. N., Simon, S. L., Janicke, D. M., and Dumont-Driscoll, M. (2011). Moderators of weight-based stigmatization among youth who are overweight and non-overweight: the role of gender, race, and body dissatisfaction. J. Dev. Behav. Pediatr. 32, 110-106. doi: 10.1097/DBP.0b013e318 2099754

Guo, W., Song, Y., Liu, F., Zhang, Z., Zhang, J., Yu, M., et al. (2015). Dissociation of functional and anatomical brain abnormalities in unaffected 
siblings of schizophrenia patients. Clin. Neurophysiol. 126, 927-932. doi: 10.1016/j.clinph.2014.08.016

Haaxma, C. A., Bloem, B. R., Borm, G. F., Oyen, W. J., Leenders, K. L., Eshuis, S., et al. (2007). Gender differences in Parkinson's disease. J. Neurol. Neurosurg. Psychiatry 78, 819-824. doi: 10.1136/jnnp.2006.103788

Hagger-Johnson, G., Deary, I. J., Davies, C. A., Weiss, A., and Batty, G. D. (2014). Reaction time and mortality from the major causes of death: the NHANES-III study. PLoS ONE 9:e82959. doi: 10.1371/journal.pone.0082959

Hajnal, A., Margas, W. M., and Covasa, M. (2008). Altered dopamine D2 receptor function and binding in obese OLETF rat. Brain Res. Bull. 75, 70-76. doi: 10.1016/j.brainresbull.2007.07.019

Hampson, E., and Morley, E. E. (2013). Estradiol concentrations and working memory performance in women of reproductive age. Psychoneuroendocrinology 38, 2897-2904. doi: 10.1016/j.psyneuen.2013.07.020

Harb, M. R., and Almeida, O. F. (2014). Altered motivation masks appetitive learning potential of obese mice. Front. Behav. Neurosci. 8:377. doi: 10.3389/fnbeh.2014.00377

Hautzinger, M. (1995). Beck-Depressions-Inventar. Bern; Goöttingen: Huber.

Horstmann, A., Busse, F. P., Mathar, D., Müller, K., Lepsien, J., Schlögl, H., et al. (2011). Obesity-related differences between women and men in brain structure and goal-directed behavior. Front. Hum. Neurosci. 5:58. doi: 10.3389/fnhum.2011.00058

Horstmann, A., Dietrich, A., Mathar, D., Pössel, M., Villringer, A., and Neumann, J. (2015a). Slave to habit? Obesity is associated with decreased behavioural sensitivity to reward devaluation. Appetite 87, 175-183. doi: 10.1016/j.appet.2014.12.212

Horstmann, A., Fenske, W. K., and Hankir, M. K. (2015b). Argument for a nonlinear relationship between severity of human obesity and dopaminergic tone. Obes. Rev. 16, 821-830. doi: 10.1111/obr.12303

Howell, N. A., Worbe, Y., Lange, I., Tait, R., Irvine, M., Banca, P., et al. (2013). Increased ventral striatal volume in college-aged binge drinkers. PLoS ONE 8:e74164. doi: 10.1371/journal.pone.0074164

Jacobs, E., and D'Esposito, M. (2011). Estrogen shapes dopamine-dependent cognitive processes: implications for women's health. J. Neurosci. 31, 5286-5293. doi: 10.1523/JNEUROSCI.6394-10.2011

Johnson, S. C., Saykin, A. J., Baxter, L. C., Flashman, L. A., Santulli, R. B., McAllister, T. W. C., et al. (2000). The relationship between fMRI activation and cerebral atrophy: comparison of normal aging and alzheimer disease. Neuroimage 11, 179-187. doi: 10.1006/nimg.1999.0530

Kalpouzos, G., Persson, J., and Nyberg, L. (2012). Local brain atrophy accounts for functional activity differences in normal aging. Neurobiol. Aging 33, 623.e1-623.e13. doi: 10.1016/j.neurobiolaging.2011.02.021

Kamijo, K., Pontifex, M. B., Khan, N. A., Raine, L. B., Scudder, M. R., Drollette, E. S., et al. (2014). The negative association of childhood obesity to cognitive control of action monitoring. Cereb. Cortex 24, 654-662. doi: $10.1093 /$ cercor/bhs 349

Khode, V., Ramdurg, S., Parakh, R., Ruikar, K., and Anupama, D. (2012). Chronoscopic reading in whole body reaction times in detecting cognitive dysfunction in metabolic syndrome: a case control study. Indian J. Med. Sci. 66, 222-2229. doi: 10.4103/0019-5359.115215

Kober, H., Mende-Siedlecki, P., Kross, E. F., Weber, J., Mischel, W., Hart, C. L., et al. (2010). Prefrontal-striatal pathway underlies cognitive regulation of craving. Proc. Natl. Acad. Sci. U.S.A. 107, 14811-14816. doi: 10.1073/pnas.1007779107

Kurniawan, I. T., Guitart-Masip, M., and Dolan, R. J. (2011). Dopamine and effortbased decision making. Front. Neurosci. 5:81. doi: 10.3389/fnins.2011.00081

la Fleur, S. E., Vanderschuren, L. J., Luijendijk, M. C., Kloeze, B. M., Tiesjema, B., and Adan, R. A. (2007). A reciprocal interaction between foodmotivated behavior and diet-induced obesity. Int. J. Obes. 31, 1286-1294. doi: $10.1038 /$ s.ijo. 0803570

Latagliata, E. C., Valzania, A., Pascucci, T., Campus, P., Cabib, S., and Puglisi-Allegra, S. (2014). Stress-induced activation of ventral tegmental muopioid receptors reduces accumbens dopamine tone by enhancing dopamine transmission in the medial pre-frontal cortex. Psychopharmacology (Berl). 231, 4099-4108. doi: 10.1007/s00213-014-3549-7

Lieberman, D. L., Tybur, J. M., and Latner, J. D. (2012). Disgust sensitivity, obesity stigma, and gender: contamination psychology predicts weight bias for women, not men. Obesity 20, 1803-1814. doi: 10.1038/oby.2011.247
Loxton, N. J., and Dawe, S. (2006). Reward and punishment sensitivity in dysfunctional eating and hazardous drinking women: associations with family risk. Appetite 47, 361-371. doi: 10.1016/j.appet.2006.05.014

Maril, S., Hassin-Baer, S., Cohen, O. S., and Tomer, R. (2013). Effects of asymmetric dopamine depletion on sensitivity to rewarding and aversive stimuli in Parkinson's disease. Neuropsychologia 51, 818-824. doi: 10.1016/j.neuropsychologia.2013.02.003

Massar, S. A., Libedinsky, C., Weiyan, C., Huettel, S. A., and Chee, M. W. (2015). Separate and overlapping brain areas encode subjective value during delay and effort discounting. Neuroimage 120, 104-113. doi: 0.1016/j.neuroimage.2015.06.080

Matton, A., Goossens, L., Braet, C., and Vervaet, M. (2013). Punishment and reward sensitivity: are naturally occurring clusters in these traits related to eating and weight problems in adolescents? Eur. Eat. Disord. Rev. 21, 184-194. doi: 10.1002/erv.2226

Nederkoorn, C., Coelho, J. S., Guerrieri, R., Houben, K., and Jansen, A. (2012). Specificity of the failure to inhibit responses in overweight children Appetite 59, 409-413. doi: 10.1016/j.appet.2012.05.028

Nagano-Saito, A., Dagher, A., Booij, L., Gravel, P., Welfeld, K., Casey, K. F., et al. (2013). Stress-induced dopamine release in human medial prefrontal cortex-18F-fallypride/PET study in healthy volunteers. Synapse 67, 821-830. doi: 10.1002/syn.21700

Narayanaswami, V., Thompson, A. C., Cassis, L. A., Bardo, M. T., and Dwoskin, L. P. (2013). Diet-induced obesity: dopamine transporter function, impulsivity and motivation. Int. J. Obes. 37, 1095-1103. doi: 10.1038/ijo.2012.178

Ness, A. R., Leary, S. D., Mattocks, C., Blair, S. N., Reilly, J. J., Wells, J., et al. (2007). Objectively measured physical activity and fat mass in a large cohort of children. PLoS Med. 4:e97. doi: 10.1371/journal.pmed.0040097

Nummenmaa, L., Hirvonen, J., Hannukainen, J. C., Immonen, H., Lindroos, M. M., Salminen, P., et al. (2012). Dorsal striatum and its limbic connectivity mediate abnormal anticipatory reward processing in obesity. PLoS ONE 7:e31089. doi: 10.1371/journal.pone.0031089

Ochner, C. N., Stice, E., Hutchins, E., Afifi, L., Geliebter, A., Hirsch, J., et al. (2012). Relation between changes in neural responsivity and reductions in desire to eat high-calorie foods following gastric bypass surgery. Neuroscience 209, 128-135. doi: $10.1016 /$ j.neuroscience.2012.02.030

Oldfield, R. C. (1971). The assessment and analysis of handedness: the Edinburgh inventory. Neuropsychologia 9, 97-113. doi: 10.1016/0028-3932(71)90067-4

Ouwehand, C., and de Ridder, D. T. (2008). Effects of temptation and weight on hedonics and motivation to eat in women. Obesity 16, 1788-1793. doi: $10.1038 /$ oby.2008.316

Paul, T., and Thiel, A. (2005). EDI-2. Eating Disorder Inventory-2. Göttingen: Hogrefe.

Perciavalle, V., Coco, M., Alagona, G., Maci, T., and Perciavalle, V. (2010). Gender differences in changes of motor cortex excitability during elevated blood lactate levels. Somatosens. Mot. Res. 27, 106-110. doi: 10.3109/08990220.2010.507102

Pruessner, J. C., Champagne, F., Meaney, M. J., and Dagher, A. (2013). Dopamine release in response to a psychological stress in humans and its relationship to early life maternal care: a positron emission tomography study using [11C]raclopride. J. Neurosci. 24, 2825-2831. doi: 10.1523/JNEUROSCI.342203.2004

Pujol, N., Penadés, R., Rametti, G., Catalán, R., Vidal-Piñeiro, D., Palacios, E., et al. (2013). Inferior frontal and insular cortical thinning is related to dysfunctional brain activation/deactivation during working memory task in schizophrenic patients. Psychiatry Res. 214, 94-101. doi: 10.1016/j.pscychresns.2013.06.008

Roth, R. H., Tam, S. Y., Ida, Y., Yang, J. X., and Deutch, A. Y. (1988). Stress and the mesocorticolimbic dopamine systems. Ann. N. Y. Acad. Sci. 537, 138-147. doi: 10.1111/j.1749-6632.1988.tb42102.x

Rothemund, Y., Preuschhof, C., Bohner, G., Bauknecht, H. C., Klingebiel, R., Flor, H., et al. (2007). Differential activation of the dorsal striatum by highcalorie visual food stimuli in obese individuals. Neuroimage 37, 410-421. doi: 10.1016/j.neuroimage.2007.05.008

Salamone, J. D., and Correa, M. (2012). The mysterious motivational functions of mesolimbic dopamine. Neuron 76, 470-485. doi: 10.1016/j.neuron.2012.10.021

Salamone, J. D., Correa, M., Farrar, A., and Mingote, S. M. (2007). Effort-related functions of nucleus accumbens dopamine and associated forebrain circuits. Psychopharmacology (Berl). 191, 461-482. doi: 10.1007/s00213-006-0668-9 
Salamone, J. D., Cousins, M. S., McCullough, L. D., Carriero, D. L., and Berkowitz, R. J. (1994). Nucleus accumbens dopamine release increases during instrumental lever pressing for food but not free food consumption. Pharmacol. Biochem. Behav. 49, 25-31. doi: 10.1016/0091-3057(94)90452-9

Schäfer, A., Vaitl, D., and Schienle, A. (2010). Regional grey matter volume abnormalities in bulimia nervosa and binge-eating disorder. Neuroimage 50, 639-643. doi: 10.1016/j.neuroimage.2009.12.063

Schulz, P., Schlotz, W., and Becker, P. (2004). TICS. Trierer Inventar zum Chronischen Stress. Göttingen: Hogrefe.

Schweimer, J., and Hauber, W. (2006). Dopamine D1 receptors in the anterior cingulate cortex regulate effort-based decision making. Learn. Mem. 13, 777-782. doi: 10.1101/lm.409306

Shafiei, N., Gray, M., Viau, V., and Floresco, S. B. (2012). Acute stress induces selective alterations in cost/benefit decision-making. Neuropsychopharmacology 37, 2194-2209. doi: 10.1038/npp.2012.69

Shin, A. C., Townsend, R. L., Patterson, L. M., and Berthoud, H. R. (2011). "Liking" and "wanting" of sweet and oily food stimuli as affected by highfat diet-induced obesity, weight loss, leptin, and genetic predisposition. Am. J. Physiol. Regul. Integr. Comp. Physiol. 301, 1267-1280. doi: 10.1152/ajpregu.003 14.2011

Silverman, D. H., Geist, C. L., Kenna, H. A., Williams, K., Wroolie, T., Powers, B. L., et al. (2011). Differences in regional brain metabolism associated with specific formulations of hormone therapy in postmenopausal women at risk for AD. Psychoneuroendocrinology 36, 502-513. doi: 10.1016/j.psyneuen. 2010.08.002

Skatrud-Mickelson, M., Benson, J., Hannon, J. C., and Askew, E. W. (2011). A comparison of subjective and objective measures of physical exertion. J. Sports Sci. 29, 1635-1644. doi: 10.1080/02640414.2011.609898

Spreckelmeyer, K. N., Krach, S., Kohls, G., Rademacher, L., Irmak, A., Konrad, K., et al. (2009). Anticipation of monetary and social reward differently activates mesolimbic brain structures in men and women. Soc. Cogn. Affect. Neurosci. 4, 158-165. doi: 10.1093/scan/nsn051

Stice, E., Spoor, S., Bohon, C., Veldhuizen, M. G., and Small, D. M. (2008). Relation of reward from food intake and anticipated food intake to obesity: a functional magnetic resonance imaging study. J. Abnorm. Psychol. 117, 924-935. doi: $10.1037 / \mathrm{a} 0013600$

Strobel, A., Beauducel, A., and Debener, S. (2001). BIS/BAS. Eine deutschsprachige Version des BIS/BAS-Fragebogens von Carver und White. Z. Diff. Diagnost. Psychol. 22, 216-227. doi: 10.1024//0170-1789.22.3.216

Swann, N., Tandon, N., Canolty, R., Ellmore, T. M., McEvoy, L. K., Dreyer, S., et al. (2009). Intracranial EEG reveals a time- and frequency-specific role for the right inferior frontal gyrus and primary motor cortex in stopping initiated responses. J. Neurosci. 29, 12675-12685. doi: 10.1523/JNEUROSCI.3359-09.2009

Sweet, L. H., Hassenstab, J. J., McCaffery, J. M., Raynor, H. A., Bond, D. S., Demos, K. E., et al. (2012). Brain response to food stimulation in obese, normal weight, and successful weight loss maintainers. Obesity 20, 2220-2225. doi: 10.1038/oby.2012.125

Tomer, R., Slagter, H. A., Christian, B. T., Fox, A. S., King, C. R., Murali, D. J., et al. (2014). Love to win or hate to Lose? Asymmetry of dopamine D2 receptor binding predicts sensitivity to reward versus punishment. J. Cogn. Neurosci. 26, 1039-1048. doi: 10.1162/jocn_a_00544
Tomiyama, A. J., Dallman, M. F., and Epel, E. S. (2011). Comfort food is comforting to those most stressed: evidence of the chronic stress response network in high stress women. Psychoneuroendocrinology 36, 1513-1519. doi: 10.1016/j.psyneuen.2011.04.005

Treadway, M. T., Buckholtz, J. W., Cowan, R. L., Woodward, N. D., Li, R., Ansari, M. S., et al. (2012). Dopaminergic mechanisms of individual differences in human effort-based decision-making. J. Neurosci. 32, 6170-6176. doi: 10.1523/JNEUROSCI.6459-11.2012

Treadway, M. T., Buckholtz, J. W., Schwartzman, A. N., Lambert, W. E., and Zald, D. H. (2009). Worth the "EEfRT"? The effort expenditure for rewards task as an objective measure of motivation and anhedonia. PLoS ONE 4:e6598. doi: 10.1371/journal.pone.0006598

Uban, K. A., Rummel, J., Floresco, S. B., and Galea, L. A. M. (2012). Estradiol modulates effort-based decision making in female rats. Neuropsychopharmacology 37, 390-401. doi: 10.1038/npp.2011.176

Vucetic, Z, Kimmel, J., and Reyes, T. M. (2011). Chronic high-fat diet drives postnatal epigenetic regulation of $\mu$-opioid receptor in the brain. Neuropsychopharmacology 36, 1199-1206. doi: 10.1038/npp.2011.4

Walton, M. E., Bannerman, D. M., Alterescu, K., and Rushworth, M. F. (2003). Functional specialization within medial frontal cortex of the anterior cingulate for evaluating effort-related decisions. J. Neurosci. 23, 6475-6579.

Walton, M. E., Bannerman, D. M., and Rushworth, M. F. (2002). The role of rat medial frontal cortex in effort-based decision making. J. Neurosci. 22, 10996-11003.

Walton, M. E., Kennerley, S. W., Bannerman, D. M., Phillips, P. E., and Rushworth, M. F. (2006). Weighing up the benefits of work: behavioral and neural analyses of effort-related decision making. Neural Netw. 19, 1302-1314. doi: 10.1016/j.neunet.2006.03.005

Wang, G. J., Volkow, N. D., Logan, J., Pappas, N. R., Wong, C. T., Zhu, W., et al. (2001). Brain dopamine and obesity. Lancet 357, 354-357. doi: 10.1016/S01406736(00)03643-6

Wardle, M. C., Treadway, M. T., and de Wit, H. (2012). Caffeine increases psychomotor performance on the effort expenditure for rewards task. Pharmacol. Biochem. Behav. 102, 526-531. doi: 10.1016/j.pbb.2012.06.016

Warne, J. P. (2009). Shaping the stress response: interplay of palatable food choices, glucocorticoids, insulin and abdominal obesity. Mol. Cell. Endocrinol. 5, 137-146. doi: 10.1016/j.mce.2008.09.036

Zeger, S. L., and Liang, K. Y. (1986). Longitudinal data analysis for discrete and continuous outcomes. Biometrics 42, 121-130. doi: 10.2307/2531248

Conflict of Interest Statement: The authors declare that the research was conducted in the absence of any commercial or financial relationships that could be construed as a potential conflict of interest.

Copyright (C) 2016 Mathar, Horstmann, Pleger, Villringer and Neumann. This is an open-access article distributed under the terms of the Creative Commons Attribution License (CC BY). The use, distribution or reproduction in other forums is permitted, provided the original author(s) or licensor are credited and that the original publication in this journal is cited, in accordance with accepted academic practice. No use, distribution or reproduction is permitted which does not comply with these terms. 